\title{
ESCRITAS DE SI MESMO: OS ADOLESCENTES E SEUS BLOGS
}

\author{
WRITING ABOUT THE SELF-TEENAGERS AND THEIR BLOGS \\ ESCRIBIR SOBRE UNO MISMO: LOS ADOLESCENTES Y SUS BLOGS \\ Elisa Aires Rodrigues de Freitas* \\ Luiz Carlos Avelino da Silva**
}

\section{RESUMO}

A escrita em diários é uma forma de expressão utilizada pelos adolescentes desde longa data. $\mathrm{Na}$ contemporaneidade, o diário migrou do papel para a internet, nos chamados blogs. Nesse artigo se discute a adolescência enquanto uma etapa da construção da identidade e o papel que os diários íntimos eletrônicos vêm adquirindo nos processos de sua elaboração. Seu objetivo foi investigar essas vivências e descrever as funçôes que as escritas em blogs assumem na vida desses adolescentes. Foram analisados os blogs de quatro adolescentes segundo um referencial psicanalítico. A conclusão indica que os blogs podem funcionar como espaço de elaboração para pensar e conhecer as experiências emocionais, funcionando também como análogo ao espaço potencial teorizado por Winnicott (1967/1975). A análise sugere que a função da escrita em blogs está ligada às tentativas dos adolescentes em elaborar as mudanças pelas quais passam e ao processo de crescimento.

Palavras-chave: adolescência; blogs; identidade.

\section{Abstract}

Writing in diaries is a form of expression. That has used by teenagers for a long time now. Actually, the diary has migrated from paper to the internet, in the so-called blogs. This article discusses teenage as a phase of the construction of identity and the role that intimate electronic diaries in the processes of elabora-

* Mestre em Psicologia Aplicada, Uberlândia, MG, Brasil.

** Universidade Federal de Uberlândia, Uberlândia, MG, Brasil. 
tion. The objective of this work was to investigate these experiences and describe the functions that the blogs writing have in the lives of the teenagers. Where analyzed four blogs made by teenagers following a psychoanalytic reference. The conclusion indicates that the blogs might work a space to elaborate to think and to acknowledge emotional experiences, working also as an analogue to the potential space" theorized by Winnicott (1967/1975). The analysis suggests that the function of writing in blogs is linked to the attempts to elaborate the changings the teenagers go through and to the process of growth.

Keywords: teenagers; blogs; identity.

\section{RESUMEN}

Escribir en diarios es una forma de expresión utilizada por los adolescentes hace mucho tiempo. En la época contemporánea, el diario de papel ha migrado hacia internet por medio de los llamados blogs. Este artículo discute la adolescencia como una etapa de la construcción de la identidad, como también, el papel que los diarios electrónicos están adquiriendo en el proceso de elaboración que esto implica. Su objetivo fue el de investigar estas experiencias y describir las funciones que las escrituras en los blogs toman en la vida de estos adolescentes. Se analizaron blogs de cuatro adolescentes de acuerdo con el marco teórico del psicoanálisis. La conclusión indica que los blogs pueden servir como una preparación para pensar acerca de las experiencias, del funcionamiento emocional y también como análogo al espacio potencial teorizado por Winnicott (1967/1975). El análisis realizado sugiere que la función de la escritura en blogs está vinculada a los intentos de los adolescentes para elaborar los cambios que experimentan y el proceso de crecimiento.

Palabras clave: adolescencia; blogs; identidad.

\section{Introdução}

Este estudo surge da necessidade de compreender as vivências comuns às pessoas quando chegam à adolescência. Etapa que pode ser vivenciada de forma rica e propiciar um bom desenvolvimento psíquico ou de forma perigosa e traumática em que este bom desenvolvimento para o mundo adulto fica comprometido. A adolescência é definida como um período marcado por uma revolução biopsicossocial em que a identidade do sujeito passa por transformaçôes provenientes de uma dimensão psicobiológica, influenciada por um contexto histórico, 
econômico, social e cultural inerente ao lugar e ao tempo em que a pessoa vive (Outeiral, 2003; Levisky, 2004; Aberastury \& Knobel, 1981).

A perda da identidade infantil, oriunda das modificaçóes corporais e das novas demandas sociais, implica a busca de uma nova identidade que, segundo Aberastury e Knobel (1981), vai se construindo consciente e inconscientemente. A estruturação da identidade é uma das tarefas primordiais da adolescência. Para Outeiral (2003, p. 63), "embora esta comece a ser construída desde o início da vida do indivíduo, é na adolescência que ela se define e se encaminha para um perfil mais definido, tornando esta experiência um dos elementos principais do processo adolescente". O sentimento de identidade se organiza por uma série de identificaçóes, que desde o início do desenvolvimento foram incorporando-se ao sujeito, inicialmente por meio dos pais e depois da sociedade.

É importante observar, também, como os valores contemporâneos influenciam a formação da identidade. Outeiral (2003) apresenta que estamos em um período que tanto a sociedade quanto a cultura passam por intensas transformaçóes de paradigmas e valores e que estes incidem no processo adolescente. Apontando para uma nova configuração social, observa-se que a internet tem transformado nossas formas de ser, de ver o mundo e de nos vermos nele. Novos conceitos, tais como ciberespaço, virtualidade e hipertexto, foram surgindo. Um espaço onde se opera sobre a lógica da síntese, da agilidade, da fragilidade fez com que o mundo fora desse espaço absorvesse, também, esses conceitos, o que influenciou as formas de ser e de pensar dos sujeitos do século XXI. Autores como Levy (2007), Outeiral (2003) e Calligaris (2000) têm discutido o impacto da cultura atual sobre o processo adolescente que, por oferecer objetos empobrecidos de identificação, acaba por provocar fracasso na capacidade simbólica, dificultando, assim, a constituição da identidade.

Os avanços tecnológicos e uma maior difusão da internet configuram, a cada dia, mais possibilidades para o uso do espaço virtual, principalmente novas formas de comunicação e maneiras de relacionar-se. Interessados em observar essas vivências da adolescência na atualidade, decidimos encontrá-los onde eles estão, ou seja, nas páginas da internet. Dentre alguns sites pessoais e de relacionamentos optamos pelo blog (utilizado como diário íntimo) por tratar-se de um espaço cuja proposta é: adolescentes falarem sobre eles mesmos. Então, nós os teríamos narrando a si próprios.

O blog é uma página da Web atualizada frequentemente e composta de pequenos textos apresentados em ordem cronológica inversa. Um blog típico combina texto, imagens e links para outros blogs. Nos blogs observam-se pequenos textos, escritos de forma direta, rápida, em uma linguagem coloquial do texto oral, 
repletos de sinais e símbolos. A capacidade dos leitores de deixarem comentários é uma parte importante para os blogueiros. Para Schittine (2004, p. 13) "o novo diário íntimo gera um relacionamento de mão dupla, entre um autor disposto a contar sua vida íntima e um público desconhecido que se dispóe a comentá-la”. Os leitores pretendem encontrar nos blogs algo de si mesmo e no momento em que o diarista conta sobre o seu cotidiano é que os captura. Freud (1908/2006), em seu artigo "Escritores criativos e devaneios", alega ser o grande escritor aquele que mais proporciona uma identificação com os personagens presentes na obra. "Escritores criativos seriam aqueles que produzem histórias com personagens que vão permitir ao leitor um deleite identificatório" (Freud, 1908/2006, p. 135). Nos blogs, os adolescentes contam sobre seu cotidiano, pensamentos, colocam poemas, fotos, imagens, em uma colorida expressão de seu mundo interno. Autoras como Braga (2009) e Poli (2005) abordam que a construção do site pessoal do adolescente remete à busca por sua identidade. $\mathrm{O}$ "quem sou eu" transparece em páginas constantemente atualizadas, com layouts quase sempre modificados, coloridos, personalizados, refletindo a visão do blogueiro sobre si e o que deseja transmitir ao outro.

Os trabalhos de Nicolaci-Da-Costa (2005), Romão-Dias (2007) e Prange (2003) têm uma análise em comum: a de que a escrita on-line é uma importante fonte de autoconhecimento. Nessas três investigaçóes fica claro que a escrita on-line é, de uma forma ou de outra, geralmente usada para falar de si (não importa se o que é dito corresponde à realidade ou se é uma construção de personagens) em programas interativos. Quando o usuário está interagindo com diferentes interlocutores, esse falar de si leva-o a ter diferentes retornos sobre o que diz. O prazer de escrever, de interagir, de pesquisar, de viver on-line atravessa todas essas pesquisas.

A escrita pode ser pensada como uma forma de comunicar e expressar as emoçóes em que o significado se constitui e se transforma através de uma capacidade de contar suas vivências de forma criativa. Segundo Freud (1908/2006), a obra literária seria como um devaneio que daria continuidade ou substituiria o brincar infantil. Através de seus escritos, o autor estaria apresentando suas fantasias. Podemos considerá-la então como uma forma de acesso ao pensamento inconsciente e também como expressão do processo de elaboração. A escrita é uma forma em que a mente se empenha na tentativa de lidar com os conflitos dando-lhes uma representação gráfica, um passo em direção à pensabilidade. $\mathrm{O}$ adolescente, em seu momento de mudanças com a perda do corpo e papéis infantis, vivendo o luto pela fantasia da bissexualidade e pelos pais da infância, pode encontrar nos diários/blogs um ponto de ancoragem. Observamos que alguns deles utilizam os diários/blogs como um espaço continente, conforme teorizado 
por Bion (1967/1988). Em uma analogia, pensamos o blog como um espaço acolhedor em que o próprio ato de escrever e a "presença" de um suposto interlocutor contribuem para a nomeação e elaboração dessas vivências.

Reconhecer por meio da escrita a existência de um espaço intermediário entre o mundo interno e o externo parece importante para esses adolescentes, pois possibilita a capacidade de usá-lo como suporte para uma travessia entre os laços familiar e o social, entre o corpo infantil e o adulto. Nesse sentido, a escrita na adolescência cumpriria uma função análoga à do espaço potencial (Winnicott, 1967/1975), suavizando a sensação de perda, acompanhando e facilitando a despedida dos objetos da infância, podendo intermediar uma forma de comunicação de vivências desconhecidas, de sofrimentos e dores. A escrita possibilita, também, uma aliança com os aspectos mais saudáveis do sujeito, integrando suas vivências e transformando-as em experiências reparadoras.

Se a adolescência pode ser pensada como um trabalho psíquico em que as mudanças reais precisam ser simbolizadas, a escrita em diários funciona como uma forma de procurar dar sentido a essas experiências. Chiapello (2007) destaca que é graças a nossa capacidade de simbolizar que acontece boa parte do nosso processo de elaboração psíquica. A possibilidade de ressignificar as experiências permite a abertura para qualidade de pensamentos, no sentido bioniano, cada vez mais evoluída. Escrevendo em blogs, o adolescente pode criar um lugar para si próprio e ser reconhecido nele. Ser reconhecido pelo outro é uma necessidade básica do ser humano, porém de fundamental importância na infância e adolescência devido à estruturação do psiquismo, como mostram autores de diferentes escolas psicanalíticas, como Bion (1967/1988), Winnicott (1967/1975) e Lacan (1966/1995), que, sem sustentarem necessariamente as mesmas posiçóes, enfatizam a importância do outro na estruturação do sujeito. Zimerman (2010), ao estudar a importância do vínculo do reconhecimento, caracteriza as vicissitudes da relação primordial mãe-bebê, base de todos os outros vínculos do ser humano. Sua teoria enfoca quatro vértices: reconhecimento de si (dar sentido às próprias experiências sensório-emocionais); reconhecimento do outro como diferente de si mesmo; ser reconhecido ao outro (ser grato) e ser reconhecido pelos outros. As escritas em blogs permitem aos adolescentes experimentarem as quatro funções. À medida que escrevem e entram em contato com suas emoçóes, podem se reconhecer nelas e ampliar cada vez mais a resposta para o quem sou eu. Um maior conhecimento de si possibilita reconhecer o outro como diferente. $\mathrm{O}$ fato de os blogs estarem em um espaço público oportuniza ser reconhecido em suas potencialidades e deficiências. $\mathrm{O}$ contato com o outro que o vê favorece o sentimento de existência e gratidão. 
Mesmo sem poder ser naturalizada, no mundo ocidental a adolescência tem se caracterizado por ser uma fase de transição. As perdas de um estado infantil exigem que o adolescente faça uma elaboração de luto, o que implica em um alto nível de investimento psíquico que, na adolescência, vem a ser bastante ansiógeno, devido ao fato de o aparelho psíquico desse sujeito encontrar-se em transformação. $\mathrm{O}$ adolescente deverá procurar, agora, em outras relações, fora do núcleo familiar, novas identificaçóes para a construção de sua identidade (Aberastury \& Knobel, 1981). Na busca da identidade adulta, ele necessitará desprender-se de suas partes primitivas e substituí-las por novos ideais, fruto de suas experiências. Estas são adquiridas à medida que ele se permite realizar novas descobertas, que vêm acompanhadas de conquistas e fracassos na sua vida.

Apesar da emergência e importância do uso do espaço virtual pelos adolescentes sob a forma de escrita em blogs, ainda são poucos os trabalhos que tratam desse tema. Entre esses, podemos destacar o de Komesu (2010), que discute a "liberdade de expressão", comumente associada às práticas de escrita na internet, a exemplo de blogs. Sob a perspectiva da análise do discurso, Di Lúccio e Nicolaci-Da-Costa (2007) investigam os impactos que a escrita digital e a tela do computador, como suporte textual, têm sobre escritores e leitores, concluindo que raramente há interação entre eles. Em outro trabalho, Di Lúccio e Nicolaci-Da-Costa (2010) discutiram a importância dos blogs como suporte textual, entendendo que novos suportes geram novas formas de ler e escrever, concluindo diferentemente que, nesses, os escritores, ao mesmo tempo que escrevem, leem regularmente outros blogs e interagem com os autores, formando-se assim uma comunidade de escritores/leitores. Refletindo sobre o suporte material na prática da escrita de si e a dimensão espaço-temporal que o envolve, Lima e Santiago (2009) veem os blogs como textos fragmentados, descontínuos, móveis e abertos, escritos no ciberespaço e lançados no espaço público. Consideraram que na passagem do diário tradicional ao público ocorre uma passagem da linearidade à espacialidade e investigaram o efeito disso no estatuto do sujeito. Cairoli e Gaurer (2009) refletem sobre a escrita em blogs e seu papel na constituição do sujeito adolescente. Dialogando com a Psicanálise assinalaram as mudanças vividas pelos adolescentes enquanto um evento subjetivo, a partir do enlace dessas transformações com as escritas feitas.

Nessa pesquisa buscou-se a articulação entre a adolescência, o uso que ela faz dos blogs e as teorizaçôes psicanalíticas, em um formato espelhado em estudos de casos, ainda que ele náo sejam tecnicamente isso. Por meio de uma leitura atenta dos blogs nos propusemos a identificar aspectos da escrita em que adolescentes contam sobre si mesmos. O objetivo foi observar e analisar essas vivências e descrever as funções que as escritas em blogs assumem em suas vidas. 


\section{Método}

A pesquisa psicanalítica permite ao investigador ir ao encontro do objeto de investigação, no qual deverá "interpretar a polissemia das situações observadas" como também mostrar "em que sentidos há sentido" (Rezende, 1993, p. 105 e 106). É importante enfatizar que, na pesquisa com o método psicanalítico, o investigador é afetado e transformado pelo objeto de investigação, o que mostra uma valorização da interação do pesquisador com seu objeto, e é onde a interpretação ou a pesquisa podem acontecer. $\mathrm{O}$ investigador deve possuir mais do que uma bagagem de conhecimentos, deve estar preparado para lidar com o desconhecido, o imprevisível e possuir, ainda, uma adequada atitude analítica: observar com atenção flutuante e reconhecer que sua presença muda a realidade do fenômeno observado, identificando os próprios limites diante do objeto, de forma que o conhecimento esteja sempre em construção.

Josso (2004) apresenta que as narrativas da vida são uma possibilidade de, por meio do acesso a uma particularidade, vislumbrarmos o universal. Enfatiza que uma pessoa, ao contar algo, reflete sobre ele, o que se torna um caminho para o (auto)conhecimento. O narrar-se é tratado por essa autora como um método de pesquisa em que se procura, a partir de um relato individual, analisar perspectivas históricas e dinâmicas. Levisky (2004) em sua tese de doutorado utilizou o método histórico-psicanalítico para analisar as narrativas de Guibert. Nessa pesquisa cujo material de análise é semelhante, recorremos a alguns conceitos desse autor. Ele afirma:

o investigador não tem seu paciente vivo para interagir com suas hipóteses, devendo recorrer, em síntese, aos não ditos, tentando extrair sinais de vida, do imaginário e da imaginação dos seus personagens para a configuração do contexto existente e vice-versa, para construir hipóteses, sugerir teorias e propor interpretaçóes, contando para isso com o corpo teórico conceitual da psicanálise e das informaçóes históricas que dispóe (Levisky, 2004, p. 65).

Em nosso caso, não se trata de personagens. $\mathrm{O}$ material analisado foram blogs de quatro adolescentes, com idades entre quinze e dezoito anos, que se propunham a escrever um diário pessoal e estavam disponíveis na internet. Considerou-se como um blog pessoal aquele que contivesse relatos de acontecimentos do próprio cotidiano, dos pensamentos e das emoçôes vivenciadas pelo autor. Os blogs deveriam ter no mínimo um ano de criação, os autores deveriam mantê-los atualizados e disponibilizarem um e-mail que possibilitasse o contato com o autor. 
Em obediência ao CEP-UFU e preservando o sigilo dos colaboradores, esses foram apelidados e modificamos algumas palavras utilizadas nos blogs, para evitar a identificação via sites de busca. Nossos colaboradores foram Alexandre Magno, Rosa, Senhorita K. e Arminda, e os acompanhamos por meio de narrativas que falam por si e lhes oferecem figurabilidade às angústias vividas nesse período. Ao longo desse artigo, suas falas surgem em itálico e isoladas por aspas simples. As narrativas dos blogs podem mobilizar reaçóes afetivas identificatórias ou contratransferenciais no investigador, interferindo em sua capacidade perceptiva de formular hipóteses, interpretar e comunicar o material observado. São reaçóes que podem ser consideradas equivalentes ao fenômeno vivenciado nas relaçôes transferenciais-contratransferenciais da clínica psicanalítica que podem gerar interferência na percepção e na transmissão dos aspectos observados.

$\mathrm{Na}$ análise dos blogs procuramos, a partir de nossa experiência clínica, por "momentos críticos", aferidos via nossa relação contratransferencial com o material escrito pelos adolescentes, em uma apropriação para a situação de pesquisa da proposição de Fédida (1989) para a supervisão clínica analítica. Para Laplanche e Pontalis (1967/2001, p. 102) o uso da contratransferência pelos psicanalistas se justifica uma vez que a análise é compreendida e descrita como relação em que as "reaçóes inconscientes do analista podem ser mais solicitadas". Afirmam ainda que "todos possuem no seu próprio inconsciente um instrumento com que podem interpretar as expressóes do inconsciente dos outros" (Laplanche \& Pontalis, 1967/2001, p. 102) e que "a comunicação de inconsciente para inconsciente constitui a única comunicação autenticamente psicanalítica” (Laplanche \& Pontalis, 1967/2001, p. 103).

Formalmente, evitou-se a categorização e optou-se por um espelhamento nos estudos de caso, privilegiando-se vinhetas significativas, visando permitir aos leitores novas e complementares interpretaçóes, na medida em que, sendo parte de um estudo maior, buscou-se neste artigo oferecer uma visão do trabalho completo, ainda que se o reconheça, nesse sentido, incompleto. $O$ pano de fundo teórico principal da análise foi a psicanálise inglesa, porém devido as poucas produçóes sobre o tema recorreu-se a autores de outras referências teóricas.

\section{Alexandre Magno e a dor do crescimento}

Alexandre, 18 anos, escreve em blogs desde seus 15 anos. Escreve muito bem em narrativas claras e diretas. Inicia explicando as razóes de ter construído seu blog, valorizando a escrita como um espaço de hospitalidade, tal como teori- 
zado por Lejeune (2008). 'Eu acredito que sou bastante timido e escrevo como forma de me expressar' Ele percebe suas dificuldades no contato com o outro, não sentindo nem em si mesmo e nem em um ambiente externo um espaço onde possa existir, porém não é um sentimento que paralisa. Criou um blog e nele busca encontrar um lugar onde possa falar sobre suas vivências. Ao escrever eu passei a me conhecer melhor e as pessoas também passaram a me conhecer melhor. Na minha escola fico isolado e inseguro. Fiz um blog para fazer as pessoas perceberem que tenho ideias e emoçóes como todo mundo'. Alexandre mostra que com a internet vai tentando exercer capacidades que ainda não realiza no face-a-face.

$\mathrm{O}$ contato com os blogs, especialmente com o de Alexandre demonstra o quanto o olhar e a necessidade de ser reconhecido são fundamentais para o ser humano. Ao perceber sua invisibilidade, Alexandre procura maneiras de ser visto, encontrando na escrita em blog uma maneira de se conhecer e ser reconhecido. 'Tudo que eu peço é um comentário, tudo me servirá de incentivo'.

Aos 17 anos, Alexandre narra em seu blog, angustiadamente, sobre as transformaçóes corporais da adolescência: 'Acordei hoje após um pesadelo profético. Ao levantar já me sentia mais alto e ao me ver no espelho do banheiro me achei mais barbudo, magro e alto do que eu me lembrava'. Frente a uma profecia pronta a cumprir-se ele se vê impotente diante das mudanças, as quais ocorreram sem a sua participação. Deverá agora, como nos lembra Ferrari (1996), apropriar-se de novas características físicas e de uma mente que deverá rearranjar-se para lidar com as angústias oriundas dessas transformaçóes corporais e de uma nova condição social, de forma que essa mente consiga dar sentido às experiências vividas e possibilite uma nova identidade.

Em outra postagem intitulada 'Crises juvenis', Alexandre condensa vivências importantes de um adolescente. Ele mostra o quanto o crescimento é muitas vezes sentido como repentino e assustador. Parece saber que toda a mudança refletida no espelho tem imediatamente um efeito no mundo interno, demandando reformular os conceitos que tinha a respeito de si mesmo, com citaçóes indiretas parafraseadas de poetas como Cecília Meireles e Carlos Drummond de Andrade. Vejamo-la: 'Socorro, eu me olho no espelho e não sei de quem é o rosto que está refletido, não sei se tenho melhor amigo e de quem sou fã. Não estou interessado em ninguém, mas há pouco tempo olhava para todas as meninas. Não sei se quero ser advogado, embaixador, comerciante ou astronauta. Náo tenho livro preferido, nem filme. Dizem que se trata de uma crise comum aos adolescentes e que aos poucos descobrirei quem sou eu. Só espero que eu não tome nenhum susto'. Observamos nesta postagem, também, que Alexandre está em um processo de elaboração de luto. Luto pela perda da identidade e pelo corpo infantis. Para Aberastury e Knobel 
(1981) vivenciar e elaborar um luto implica em um alto nível de investimento psíquico que, na adolescência, torna-se mais ansiógeno devido ao fato de o aparelho psíquico encontrar-se em reformulação. A superação dessas perdas é que permitirá a entrada no mundo adulto.

Em vários posts, Alexandre mostra-se com um duplo, discriminando entre um Alexandre do mundo real e o outro, o virtual, o da internet, encontrando no blog uma possibilidade de se ver e também de existir. Ele escreve: 'No mundo virtual sou um, na vida real sou outro. Compartilhamos das mesmas emoçóes, valores, desejos. Mas a diferença está em que o Alexandre real observa, escuta, sonha, analisa, mas tudo isso só com ele mesmo. $O$ da internet faz o mesmo e ainda mais, escreve sobre seus sentimentos explicitamente e sinceramente. Neste post Alexandre reafirma o blog como lugar de experimentação, no qual busca o outro e é reconhecido, tarefa que ele ainda não exerce fora do ambiente virtual. A frase nos sugere também um aspecto defensivo, na medida em que supóe que pelo blog pode dizer seus "não ditos", o que denuncia certa preocupação com o sentido que suas palavras podem ter para o outro. Ao contrário do que parece pretender mostrar, o outro virtual, o qual afirma ser o mais verdadeiro, é aquele que ele consegue controlar, corrigir, apagar e editar: o Alexandre escrito.

O fato de escrever em blog demonstra o desejo de Alexandre em encontrar o outro. Apesar de ele contrapor os termos vida real e vida na internet, o blog para ele parece ocupar um lugar de transição, em que ele pode dar sentido a suas experiências. O blog possibilita que Alexandre caminhe em direção à sociabilidade, utilizando-o como uma fresta para o mundo externo. Neste espaço ele pode conhecer suas potencialidades e ser reconhecido por elas. Como assinala Zimerman (2010), é importante que a pessoa reconheça o que preexiste dentro dela e pensava estar fora.

Alexandre nos relata que passou no Vestibular e que está namorando. Observamos que, aos poucos, ele diminuiu a quantidade de postagens e em uma delas falou sobre a saudade da menina amada: 'faltam cinzas dias para eu vê-la... cinzas dias cinzentos para que ela traga de volta todas as cores.' Lejeune (2008) aponta que muitas vezes os diários são interrompidos quando se encontra alguém com quem falar. Acreditamos que Alexandre, além de encontrar uma namorada, encontrou também recursos para viver novas relaçōes e novas experiências.

\section{Rosa e o desejo de ser grande}

Rosa, 16 anos, ao montar seu blog, diz: 'Ahhh! Nunca tive um blog! E esse pode ser apenas mais um ato de impulsividade, vejo que tenho que aprender demais. 
E quase quebrei o computador tentando decifrar rapidamente como fazer.' A construção de um blog leva-nos à associação com a busca de uma identidade e de um novo lugar a ser ocupado, característicos do processo da adolescência. Nessa fala, ela nos lembra de que tornar-se adulto é uma tarefa longa e árdua e que, muitas vezes, o adolescente se sente desamparado para realizá-la, como pensa Outeiral (2003).

'Blog pronto e agora? O que escrever?'. Rosa monta seu blog e quando está pronto não sabe o que fazer com ele. Podemos, aqui, fazer algumas associaçóes com o adolescente que tanto deseja ter um corpo adulto e agora que o tem náo sabe lidar com ele. Talvez ela ainda não soubesse responder a essa pergunta, mas lançou-se ao desafio de tentar respondê-la aos poucos, porque não é tão fácil apresentar-se, quando ainda não se sabe muito bem quem se é. Outeiral (2003, p. 24) assinala que o adolescente já tem uma identidade, mas é "uma identidade em crise, na qual o sujeito procura discriminar-se do mundo e ter seu próprio self, ser e saber quem é ele mesmo".

Em outra postagem, Rosa despede-se da infância de forma tocante. 'A princípio tudo estava normal. Meu quarto com guarda-roupa, computador, porta, janelas. De cima de uma estante uma criança me olha, com um olhar curioso para saber o que vou fazer, mas também me dando bronca, ao perceber que deixei muita coisa para trás as quais ela não queria perder. Tem um olhar risonho também, porque sabe que tudo poderá ser usado no futuro. Sonha, brinca com suas bonecas e fantasia o viver. E agora? Eu-menina? Eu-moça?'. O refúgio de que Rosa nos fala também é vivido por muitos outros adolescentes. Segundo Levy (1996) trata-se de um espaço mental protetor, ao qual se pode recorrer sempre que a ansiedade extrapolar a capacidade de tolerância. Rosa habita um corpo que desconhece e que exigirá uma reapropriação da imagem de si mesma. Talvez diferente do idealizado e que será preciso aprender a amar. Outeiral (2003, p. 24) afirma: "O corpo imaginário é mais significante que o corpo real, que, por sua vez, durante bastante tempo, continuará sendo, em parte, um desconhecido que paulatinamente ocupará seu lugar na integridade do indivíduo”. Rosa conversa com a Rosa-criança, volta-se para o seu mundo interno, liga-se ao seu passado, sabe que os sonhos da Rosinha terão que ficar para trás, mas também sabe que a menina turrona sempre fará parte dela. É, hoje, uma menina-moça turrona. Para Aberastury e Knobel (1981), só quando o adolescente aceita, simultaneamente, os dois aspectos, o de criança e o de adulto, poderá começar a aceitar as mudanças do seu corpo.

Sobre o desejo de independência, Rosa olha o mundo de fora, acha-o atraente e demonstra o desejo de arriscar ir até ele, saindo do conforto e proteção dos seus pais. 'Muitas vezes devaneio em ir sozinha para as montanhas e ficar com 
o vento e o mato, mas tenho certeza que é melhor ficar imaginando daqui de dentro do carro, do que lá cheia de carrapatos. Mas um dia eu me aventuro'. Inicialmente pensa ser esse um desafio tranquilo, mas descobre que o mundo também tem seus perigos e recua, talvez não acreditando, ainda, ter recursos suficientes. Pensando com Aberastury e Knobel (1981), cremos que Rosa somente se assegurará de sua individualidade e subjetividade de forma madura com o abandono das suas dependências infantis e a obtenção de novos vínculos que ampliem sua maneira de estar no mundo.

\section{Senhorita K. e o desejo de ser o que já se intui em si}

Senhorita K., 16 anos, em seu blog, às vezes troca a letra q pela k, e mescla textos de sua autoria com os de outros autores. Acreditamos que ela faz isso como uma forma de deixar sua marca. 'Por K? Pra K? Keria ser diferente e eskeçer de tudo'. Diferentemente dos outros blogs, Senhorita K. inicia o seu postando fotos suas, sem nada dizer. Percebemos que naquele momento se encontrava em um nível de comunicação ainda baseado no sensorial, uma maior facilidade com as imagens do que com as palavras. Aos poucos, identifica-se com pequenos trechos de outros autores e publica no seu blog. Após três meses escreve algo de sua própria autoria.

O blog em questão permitiu-nos acompanhar a busca de Senhorita K. por um espaço interno, onde as emoçóes possam ser nomeadas. Em suas narrativas foi possível acompanhar o desenvolvimento de uma condição para pensar as emoçóes, a busca de conhecer a si mesma, como também os conflitos e as descobertas trazidas pela adolescência. Ela conta o quanto as mudanças a angustiam. 'Tenho medo de me tornar quem não sou e percorrer estradas diferentes. Eu fico preocupada em não saber mais quem eu sou com o tempo'. Observamos que ela se sente muitas vezes impotente frente às mudanças: 'Gostaria de viver meu máximo, mas meu destino está definido. Parece que vivo à mercê dos desejos de outras pessoas. Como eu gostaria de ser do jeito que eu desejar e poder desenhar meus passos com menos medo'. Almejando a emancipação, ela parece se encontrar sem saída em um mundo em que vê seu destino determinado, mas que diante da sua adolescência parece significar um sofrimento de uma vida adulta na qual não se reconheça. Ela precisa buscar novas identificaçóes que possibilitem o exercício de novos papéis sociais e aceitação da sua identidade (Aberastury \& Knobel, 1981; Outeiral, 2003; Levisky, 1998).

Em uma postagem posterior, já apresenta uma maior maturidade. 'Vejo que não existe nada definido como certo e errado. Eu também posso escolher e assim fica 
melhor'. Em alguns momentos sente-se impotente, em outros demonstra a percepção de um potencial latente dentro dela. 'Essa menina que tem dúvidas e medos esconde uma mulher que está aguardando a hora certa para revelar o potencial que está dentro dela. Tornar-se mulher surge, nesse contexto, com um projeto, ainda temeroso, mas do qual não há como esquivar-se sem perder-se, já que supóe o potencial - e potência - que essa conquista pode lhe dar. Mas ainda há temor da dor que isso também pode gerar.

Na passagem de ano, ela faz uma série de promessas: '2009 preciso amadurecer. Meu corpo e minha cabeça precisam entrar em um acordo'. Novamente observamos uma fala em que Senhorita K. faz uma auto-observação, o que consequentemente poderá levar a mudanças. Integrar novos desejos a uma mente em formação demanda tempo e uma longa negociação, em que podem entrar em choque as exigências do superego com as novas pulsões, como afirma Levisky (1998). Senhorita K. precisa transformar as suas sensaçóes em pensamentos e parece ter noção sobre isso. Tratando-se de uma adolescente podemos pensar, neste momento, nas novas sensaçóes e vivências que acompanham o adolescer e que precisam ser representadas na sua mente.

No blog Senhorita K. aborda suas vivências da sexualidade: 'Falar em desejo e em sensualidade me lembra fazer amor, de sexo. Essas emoçóes, porém, muitas vezes são vistas como promíscuas. Mas há como se sentir vivo sem desejar? O que você pensa sobre isso? O que pode e o que não pode?'. Para Levisky (1998) estes sentimentos contraditórios e de culpa advêm de uma fragilidade egoica, característica desse período, particularmente quando a questão que a adolescente se coloca é referente ao tornar-se mulher.

Como outros adolescentes, Senhorita K. nos conta da sua necessidade de isolamento. $\mathrm{O}$ refúgio é utilizado pelos adolescentes como "forma de realizar todo o trabalho reflexivo e elaborativo da adolescência” (Levy, 1996, p. 229). Levy (1996) aponta a necessidade desse refúgio psíquico sempre que houver uma intensidade de estímulos para serem pensados. 'Ninguém me entende e entendem muito menos que às vezes preciso ficar sozinha. São esses momentos de solidão $k$ me dão forças'. Aos poucos, ela percebe a necessidade de pensar e integrar suas experiências.

\section{Arminda, ou a tentativa de ser normal como todo mundo}

Arminda escreve muito bem em narrativas que falam por si mesmas. $\mathrm{O}$ seu blog nos remete a crise normal da adolescência nos lembrando da obra e conceitos de Arminda Aberastury, por isso a escolha do nome fictício. Seu blog não tem fo- 
tos, apenas uma 3X4, e apresenta-se com uma frase de Drumond: 'Sou do tamanho que sinto, que vejo, que faço. E não do tamanho que os outros me enxergam'. Apesar de apresentar-se assim, acompanhamos sua luta com esse olhar do outro e com o seu próprio olhar em uma busca de se conhecer e se ver reconhecida verdadeiramente pelo olhar do outro e por si mesma. Recortamos alguns trechos em que acompanhamos isso: 'Não me importo com o que pensam de mim'. 'Outro dia me disseram que eu passo a imagem de frágil e de viver em um mundo rosa, fiquei sem chão, mas evitei chorar, para não confirmar essa imagem de indefesa'. 'Ser você já é difícil, querer que os outros aceitem suas características é impossivel, já tentei. Arminda queixa-se de não se sentir reconhecida pelo outro e tenta demonstrar-se indiferente a isso, porém a repetição do tema nos leva a pensar o quanto esse olhar que ela relata não percebê-la bem ainda a incomoda. Por não ter esse olhar introjetado, sente-se desprotegida. Mas o importante é notar que ela o busca, tanto por meio do blog como de outras vivências que nos contará. Para Winnicott (1967/1975) para o sujeito olhar criativamente o mundo deve ter internalizado a experiência de ter sido olhado.

$\mathrm{Na}$ sua primeira postagem intitulada "Ação" reproduz uma frase de Clarisse Lispector: 'Escrever é procurar entender, é procurar reproduzir o irreproduzivel, é sentir até o último fim do sentimento que permaneceria apenas vago e sufocador'. Esse trecho escolhido por ela nos dá a dimensão de uma adolescente que tem conhecimento da existência de um mundo interno e que observa a possibilidade de, por meio da escrita, dar sentido às suas emoçóes, procurando transformar algo que esteja em estado bruto em representaçóes por meio de palavras.

'Apenas uma semana que não escrevo. Mas sinto um tumulto dentro de mim'. Arminda parece saber da importância de se ter uma função mental que seja capaz de organizar as experiências que, de outra forma, ficariam apenas em um nível sensorial e sem sentido, ocupando espaços em sua mente. A escrita ajuda Arminda a entrar em contato e a elaborar suas emoçóes. Isso nos remete a Ribeiro (2009), que afirma ser por meio do processo de construção de símbolos que acontecem boa parte dos processos de elaboração psíquica, apontando que a camada simbólica da comunicação humana é conquistada frente à tolerância da dor psíquica. Com esta bela narrativa, podemos exemplificar isso: 'Preciso de inspiração, acontecimentos externos que seráo absorvidos, sentidos e depois modelados ao escrever. Atualmente tenho interiorizado tanta coisa e os transformado em sentimentos... E assim, escrevo. As palavras escapam entre os meus dedos e dessa forma eu me mantenho mais calma frente às experiências ruins. Escrevendo, socorro o meu coração'.

Em muitas postagens Arminda apresenta o quanto ainda está confusa em relação ao seu novo corpo, aos novos papéis e ao quem ela é, se criança ou se mulher. 'Talvez, meu corpo desenvolvera antes mesmo do meu eu, e com isso eu teria um 
mundo inteiro a desvendar, mas o mundo ainda teria uma menina para descobrir'. Acompanhamo-la fazendo uma trajetória da sua infância à idade atual, buscando naquelas lembranças algo que possa dar sentido à Arminda de hoje. Sabemos que na adolescência são reeditados muitos conflitos da infância, que surgem agora como possibilidade de elaboração e transformação. A perda da identidade infantil, oriunda das modificaçóes corporais e das novas demandas sociais, implica a busca de uma nova identidade que, segundo Aberastury e Knobel (1981), vai se construindo consciente e inconscientemente. $\mathrm{O}$ adolescente não deseja mais ser como determinado adulto e escolhe agora outros como novos ideais. Porém é por meio do mundo interno, construído pelos seus primeiros vínculos, que o sujeito escolherá novos estímulos para a formação de sua identidade.

No post denominado "Fragmentos de uma vida" Arminda faz uma análise de sua história e pelo título percebemos que a jovem falará de marcas que precisam ser unidas, simbolizadas e ressignificadas. Começa pela descrição dos seus primeiros anos de vida: uma casa em reforma, um pai ausente ocupado com o trabalho, uma mãe atenta, poucos amigos; e nos revela um pouco de sua personalidade: 'meus parentes sempre me criticavam por ser tímida'. Relembra a separação dos pais e diz: 'ao recordar essa história sinto-me muito triste. Náo sei como concluir o que aconteceu e talvez nunca consiga, ficando, apenas, reticências'. Arminda observa que nem tudo tem sentido, demonstrando possuir uma capacidade de tolerar não ter respostas para tudo, principalmente quando são questóes que envolvem o outro. Para Bion (1967/1988) a função do pensar resulta de uma disponibilidade do sujeito para saber o seu não saber; dessa forma, o pensar consiste em ter problemas a solucionar e não em ter soluções para os problemas. Aos nove anos, recorda a primeira apresentação de balé e aos doze anos o primeiro beijo: 'o primeiro beijo deixa suas marcas e para mim foi muito especial porque foi com o meu primeiro namorado'. Embora haja a presença, na sociedade contemporânea, de toda uma erótica que envolve o ficar do adolescente, Arminda aponta a importância do vínculo, em que as experiências podem ganhar mais sentido. 'Ele acompanhou e viveu comigo todas as mudanças do meu jeito de ser'.

Novas atividades começam a fazer parte de sua vida. Arminda conta sobre sua participação no grupo de teatro como possibilidade de vencer sua timidez. Ela está aberta para o novo e também para descobrir novas potencialidades em si mesma. 'Percorri por um mundo mágico de personagens e me dediquei ao teatro'. Dessa forma, podemos observar que ela faz bom uso deste descobrir-se, pois tenta cuidar e modificar partes dela, que ainda precisam ser desenvolvidas. Aos 15 anos, revela: 'Nesse momento foi que aprendi a lidar com pessoas de personalidades bem diferentes, a ir atrás do que eu queria, comecei a me mostrar e também a construir o 
meu castelo e fiquei com tanta vontade de conhecer o interior das pessoas que passei a analisá-las holisticamente’. Neste trecho, observamos o seu movimento de idas ao encontro do outro e recuos, mostra-se e protege-se. Busca observar as pessoas por inteiro, como também apresentar partes suas, que, talvez, ficassem escondidas. Pensamos que o crescimento ocorra assim, por meio de experimentaçóes, em momentos em que se arrisca mais e em outros em que a proteção se faz necessária. $\mathrm{O}$ importante é se permitir realizar esse movimento.

Finaliza sua retrospectiva assim: 'Muitas escolhas ainda virão... e quanta coisa ainda poderei escrever. Ao fazer essa trajetória fiquei orgulhosa de mim. Foram apenas 17 anos e minha face com cravos, meus cabelos desmazelados, unhas coloridas denunciam a idade que tenho. Contudo, ainda quero viver tanta coisa. Fico feliz por ter crescido tanto em táo pouco tempo. Sou privilegiada por ter ao meu lado pessoas que me deram oportunidade de conhecer o mundo. Mas ainda me sinto tão pequenina quando vejo que guardo as lembranças da criança que um dia fui e que, na verdade, ainda não deixei de ser'. Arminda percorre esse trajeto, valorizando as experiências anteriores como promovedoras do que ela é hoje. Demonstra gratidão à vida e às pessoas com que convive. Anseia conhecer o novo e sabe que é aquela menina cheia de dores e curiosidades a que lhe possibilitará isso. Fala de uma mente que se encontra em momentos diferentes do seu corpo, uma mente que quer dar saltos e um corpo marcado pela adolescência. Fica clara nessa retrospectiva a importância de carregar a criança de outrora dentro de si. A sua curiosidade e sua criatividade é que permitirão um mundo adulto mais rico.

Em uma despedida de fim de ano diz: 'Entre risos e lágrimas, razóes e emoçôes o ano está terminando. Ficaram dúvidas, mas também vivências que serão eternas'. Acreditar que sempre haverá algum não saber como também aprendizagens mostra que ela está em um momento mais integrado de sua mente.

\section{Conclusão}

Alexandre, Rosa, Senhorita K. e Arminda, com idades entre 15 e 18 anos, têm muitas diferenças. Alguns namoram, outros não. Alguns estão na faculdade, outros estudando muito para isso, e há aquele que ainda nem pensa nisso. Uns gostam de rock e outros preferem MPB. O que eles têm em comum é o escrever em blogs. Nesse espaço relatam vivências da própria adolescência e o papel que a escrita em um blog assume em suas vidas.

Observamos em nossas leituras a busca desses adolescentes por saber quem são, revelando suas angústias frente às mudanças corporais, aos novos papéis so- 
ciais, à elaboração de luto pelos pais da infância e identidade infantil, à emergência da sexualidade em vivências em que o corpo e a mente procuram se integrar. Analisamos que a escrita em um blog teve como função, para eles, ser uma forma de comunicar e expressar o que estão sentindo, buscando um acolhimento para suas vivências, bem como ser um processo de elaboração. Dar representação para as emoçóes envolvidas em um conflito é uma oportunidade de poder pensá-lo. A experiência vivida permanece viva na memória do sujeito, portanto agora ganhando novos sentidos e ampliaçóes à medida que ele permite ver-se no que escreve.

É muito difícil contar uma experiência por meio de palavras, e esta é uma luta constante para quem escreve. Pensamos que quando esses adolescentes escrevem sobre uma vivência abrem espaço para uma nova experiência e um novo conhecimento sobre ela. Conhecer, como vimos, é uma atividade pela qual o indivíduo torna-se consciente da sua experiência emocional e aprende com ela (Bion, 1967/1988). Então, quando lemos as narrativas dos blogs, não lemos a vivência em si, mas a criação de uma nova experiência, no seu contato com uma emoção, já com uma diferente elaboração.

Notamos que esses adolescentes fazem muitas referências ao olhar e solicitam sempre que as pessoas leiam e comentem seus escritos. Atribuímos isso à importância de ser reconhecido. Não percebemos ser uma busca de uma visibilidade espetacular, mas, ao contrário, buscam um contato, um encontro. $\mathrm{O}$ adolescente necessita muito ainda desse olhar e quer ser reconhecido por um novo grupo além dos seus laços familiares. O blog também foi associado, neste estudo, ao espaço potencial. Espaço para elaboração de objetos perdidos, espaço de proteção e de regresso sempre que necessitar. Espaço que possibilita um afastamento da realidade para poder pensar e experimentar o que ainda não foi possível por outras vias. Espaço de ficar só e ao mesmo tempo acompanhado.

Acreditamos que nos blogs a escrita inserida em um mundo virtual possibilitou para esses adolescentes uma busca e, em diferentes momentos, um encontro com as próprias emoçóes, dessa forma podendo conhecê-las e transformá-las. Pensamos tal espaço como uma produção de criatividade em que possam dar sentido às experiências vividas. Para Arminda, Senhorita K., Alexandre e Rosa a escrita cumpriu a função de um espaço potencial suavizando a sensação de perda, acompanhando-os e lhes facilitando a despedida dos objetos da infância.

\section{Referências}

Aberastury, A., \& Knobel, M. (1981). Adolescência normal-um enfoque psicanalitico. Porto Alegre: Artmed. 
Bion, W. R. (1988). Estudos psicanaliticos revisados. Rio de Janeiro: Imago. (Obra original publicado em 1967).

Braga, C. M. L. (2009). Comunicação e isolamento: uma análise clínica de diários e blogs de adolescentes. (Tese doutorado. Pontifícia Universidade Católica de Campinas, São Paulo, SP).

Cairoli P., \& Gauer G. C. (2009). A adolescência escrita em blogs. Estudos de Psicologia I, 26(2), 205-213.

Calligaris. C. (2000) A adolescência. São Paulo: Publifolha.

Chiapello, C. S. S. (2009). Simbolização e sublimação: reflexões e conjecturas. In Anais do $2^{\circ}$ Encontro do Ciclo de Conferências "Re-Evoluçōes". "Re-Evoluçôes". Recuperado em 24 de novembro, 2014 de: <http://www.sbprp.org.br/sbprp/images/online/artigo_119.pdf>.

Di Luccio, F. \& Nicolaci-Da-Costa, A. M. (2007). Escritores de blogs: interagindo com os leitores ou apenas ouvindo ecos? Psicologia Ciência e Profissão, 27(4), 664-679.

Di Luccio, F. \& Nicolaci-Da-Costa, A. M. (2010). Blogs: de diários pessoais a comunidades virtuais de escritores/leitores. Psicologia Ciência e Profissão, 30(1), 132-145.

Fédida, P. (1989). Comunicação e representação: novas semiologias em psicopatologia. São Paulo: Escuta.

Ferrari, A. B. (1996). Adolescência: o segundo desafio - considerações psicanalíticas. São Paulo-SP: Casa do Psicólogo.

Freud, S. (2006). Escritores criativos e devaneio. In S. Freud. Obras Completas, v. XXI. Rio de Janeiro: Imago. (Obra original publicada em 1908).

Josso, M. C. (2004). Experiências de vida e formação. São Paulo: Cortez.

Komesu, F. (2010). Espaços e fronteiras da "liberdade de expressão" em blogs na internet. Linguistica aplicada, 49(2), 343-357.

Lacan, J. (1995). Escritos I. Madrid: Siglo Veintiuno Editores. (Trabalho original publicado em 1966).

Laplanche, J., \& Pontalis, J. B. (2001). Vocabulário da psicanálise. São Paulo: Martins Fontes. (Trabalho original publicado em 1967).

Lejeune, P. (2008). O pacto autobiográfico - de Rousseau à internet. Belo Horizonte: UFMG.

Levisky, D. L. (1998). Adolescência - reflexôes psicanalíticas. São Paulo: Casa do Psicólogo.

Levisky, D. L. (2004) Um monge no divã - O adolescer de Guibert de Nogent (1055-1125?): uma análise histórico-psicanalítica. (Tese de doutorado. Universidade de São Paulo, São Paulo, SP).

Levy, R. (1996). Refúgios narcisistas na adolescência: entre a busca de proteção e o risco de destruição - Dilemas contratransferenciais. Revista Brasileira de Psicanálise, 30(1), 223-239.

Levy, R. (2007, janeiro). Refúgios narcisistas, destrutividade e dilemas contratransferenciais. Convegno Essere Adolescenti Oggi, Milão, Itália.

Lima, N. L., \& Santiago, A. L. B._(2009). Do diário íntimo ao blog: o sujeito entre a linearidade e a espacialidade. Revista Mal-Estar e Subjetividade, 9(3), 938-962.

Psic. Clin., Rio de Janeiro, vol. 26, N.2, P. I 39 - I 57, 20 I 4 
Nicolaci-Da-Costa, A. M. (2005). Sociabilidade virtual: separando o joio do trigo. Psicologia e Sociedade, 17(2), 50-57.

Outeiral, J. (2003). Adolescer - Estudos revisados sobre a adolescência. Rio de Janeiro: Reinventer.

Poli, M. C. (2005). Dos diários aos blogs. Revista Mente e Cérebro - O olhar adolescente - os incriveis anos de transição para a idade adulta, v. 3 - Caminhos da cognição (pp. 63-70). São Paulo: Duetto Editorial.

Prange, A. P. (2003). Da literatura aos blogs: um passeio pelo território da escrita de si. (Dissertação de Mestrado. Programa de pós-graduação em psicologia, Pontifícia Universidade Católica do Rio de Janeiro, Rio de Janeiro, RJ).

Rezende, A. M. (1993). A investigação em psicanálise: exegese, hermenêutica e interpretação. In L. Silva \& M. Emília (Eds). Investigação e psicanálise (pp. 103-118). Campinas: Papirus.

Ribeiro, P. M. M. (2009). Simbolizar, sonhar e pensar - uma visão positiva da subjetividade contemporânea. Apresentação no 2o Encontro do Ciclo de Conferências "Re-evoluçóes" (p. 1-10). Recuperado em 23 de novembro, 2014, de: <http://www.sbprp.org.br/sbprp/ images/online/artigo_120.pdf>.

Romão-Dias, D. (2007). Brincando de ser na realidade virtual - uma visão positiva da subjetividade contemporânea. (Tese de Doutorado. Pontifícia Universidade Católica do Rio de Janeiro. Rio de Janeiro, RJ).

Schittine, D. (2004). Blog: comunicação e escrita intima na internet. Rio de Janeiro: Civilização Brasileira.

Winnicott, D. W. (1975). O brincar e a realidade. Rio de Janeiro: Editora Imago. (Obra original publicada em 1967).

Zimerman, D. E. (2010). Os quatro vínculos - amor, ódio, conhecimento, reconhecimento - na psicanálise e na vida. Porto Alegre: Ed. Artmed.

Recebido em 25 de fevereiro de 2013 Aceito para publicação em 04 de junho de 2014 